Masuma H. Mammadova1, Sanan M. Ahmadov ${ }^{2}$

${ }^{1,2}$ Institute of Information Technology of ANAS, Baku, Azerbaijan

${ }^{1}$ masuma.huseyn@iit.ab.az, ${ }^{2}$ senanahmedli@yahoo.com

\title{
IMPACT OF SOCIAL MEDIA ON THE INTEGRATION OF DISABLED PEOPLE TO MODERN SOCIETY
}

The paper explores the principal impact of social media on the way disabled people integrate to the modern society. It also studies the needs and purposes of disabled people that can be met through social media. Social media technologies, devices and applications with additional functionalities designed especially for disabled people are analyzed. Possible problems that impaired people face while using social media are shown and their appropriate solution ways are given.

Keywords: disabled people, social media, assistive technologies, social networks, IT applications for disabled people.

\section{Introduction}

The emergence of the concept of "social media" depends on new Web 2.0-based technologies (RSS, blogs, etc.) and the Internet resources (online social networking, video-calling, etc.). At first glance, these two concepts differ from each other; however, their feature in common is that they simplify the information sharing among the users. At present, social media plays an exceptional role in regulating online processes. Although it has been widely used, it is a challenging task to give a full definition of this tool. Kaplan A. and Haenlein M. define the social media as Internetbased software based on the ideological and technical rules of Web2.0, and these systems should enable the generation and exchange of user data [1]. For ordinary citizens, this is "a system that helps to communicate effectively with others." Apparently, social media has different meanings for everyone.

Developing social media has created opportunities for people to access information, message, find a job, and review and download various types of media content (photos, videos, music).

The users of these systems have the opportunity to create their own databases, publish them, share them with friends and communicate in real-time anywhere. Social media, i.e., social networks have created a completely new tradition and have become one of the most important components of socialization. This fact can be observed in changing lifestyle of people and in different aspects of their activities. For example, people now communicate with each other over these networks, show their opinions on social and political issues, and share their achievements. These networks are also used to provide certain services, to conduct online meetings in companies, to obtain different content and to regulate the recruitment process.

However, lack of equal access to social networks leads to the discrimination of people and the creation of social barriers between them and the society, and the emergence of the digital inequality. Although social media is rapidly becoming popular, not all people can benefit from it. As a result, two layers have been created: those who can use it and those, who can not. The isolation of the people with limited health capabilities does not allow them to access information, enrich their knowledge or integrate into society. A person with limited health capabilities is a person who has a full or partial loss of vision, hearing, feelings and with limited movement, and cognitive disorders. These restrictions have a different effect on the way people access the computer and the social media.

When designing the social media platforms, the access of disabled people to these systems is not fully taken into account. Although their use of the network should be regarded as investment in improving the socio-economic situation of the society rather than the expenses for companies and governments. 
This article aims at examining the use of social networking for people with limited health capabilities and the role and importance of social media in their integration into society.

\section{Purposes of using social media and requirements of disabled people}

The World Health Organization reports that currently, 15 to 16 percent of the world's population has certain health restrictions. This is about 1 billion people [2]. In the corresponding report by the UN, this figure is slightly less and accounts for 10 percent [3]. At present, disabled people constitute 5.6 percent of the total population of Azerbaijan [4]. The studies conducted by the United Nations Development Program have shown that 80 percent of the world population is in developing countries, and 20 percent of the poor in the world are disabled people [5]. Disabled people often have great potential and ability to work actively in the social life, however the lack of access to information and communication prevents them to realize it.

A number of goals, needs and communication problems of people with limited health capabilities can be solved through the social media. Of course, from the prism of the social media, the social needs of the people with disabilities are directly related to their demographic (age, gender), physical and mental characteristics, education level, work ability and other indicators, which can be satisfied by various means. The goals and needs of the disabled people related to the use of social media are shown below [6-11].

Personal. These goals and requirements imply the communication with other people (written or verbal), exchange of ideas, pictures, paintings, articles and Internet resources.

Job Search and Labor Activity. Social Networks are a new tool for finding a job and establishing contact with the employer. LinkedIn.com is intended for creating new business relationships and finding a job. Currently, vacancy databases of social networks offer the jobs to be performed at home via the Internet. Social networks provide disabled people with access to different information, communication, education and work in different areas. For example, positions related to the information technology as a computer operator, webmasters, network administrator, and designer are more convenient for these people.

Education: Finding adequate employment depends on the availability of relevant knowledge and qualifications of the disabled people. The experience of Norway, the Netherlands, Finland and other developed countries shows that the remote education process can be achieved only through the use of advanced information and communication technologies (ICT). ICT provides an opportunity for the practitioner to communicate with a disabled person. The following opportunities are achieved through the social networks:

1) dissemination of information on participation in online classes;

2) uploading the information facilitating the acquisition of the material;

3) favorable conditions for discussing topics related to the course;

4) opportunities for listening to audio and video lessons.

Leisure. People with physical limitations can use the social network to watch and download entertaining videos, movies, pictures and museum exhibits, play online games, listen to songs in different genres, and watch educational videos. Today, the Internet resources available to people with disabilities provide the sharing of information and innovations between them.

Different services. People with disabilities get access to medical, legal, e-commerce and other services through the social networks. The development of different types of social media (social networks, forums, and blogs) has led to the formation of networks of professional communities. For example, specialized medical social networks bring together the doctors of different areas. These networks allow individuals with physical disabilities to take advantage of online consultations of physicians and pharmacists.

In general, the above-mentioned social media opportunities are very important for each individual, however the people with limited health need these services more. Of course, support for people with limited health capabilities through ICT and choosing the appropriate technologies 
can be identified after the reasons for disability are properly analyzed. From this point of view, it is desirable to divide the disabled into four main categories and determine the direction of social integration on each of them [12]:

- people who do not partially or completely see;

- people who do not partially or completely hear;

- people with physical disabilities;

- people with mental problems.

An analysis of the use of social media by disabled people in the listed categories indicates that each category has a different purpose for using social media.

For example, the blind can communicate with friends using social networks (Twitter, Facebook) and share certain information about themselves. Visually impaired people look for jobs or expand their careers through LinkedIn. That is, these systems are really of great importance to increase the well-being of people with limited health capabilities [13].

Studies have shown that disabled people with intellectual disabilities have difficulty to communicate face-to-face with other people. Communicating with others on the Internet and social networks may eliminate this problem. As a result, they can comfortably communicate with others.

There is one thing in common in the use of social media. Thus, social media plays a major role in integrating these individuals into society, regardless of the purpose of use of those with limited health capabilities.

\section{Technology for using social media for people with limited health capabilities}

Modern scientific and technical development creates opportunities for people with disabilities to have equal opportunities in society with healthy people. Given the physical limitations of this category of people, technologies have been created that enable the control of computer hardware, data entry and processing, and software compatibility with certain systems. These technologies, which were first introduced to people with disabilities in 1998, were called "assistive technologies", and a great deal of work was done in this direction. Assistive technologies are a common term that incorporates auxiliary, adaptive and rehabilitation devices [15]. Auxiliary devices are intended for people with all physical and mental defects, while adaptive devices are designed for the needs of certain individuals based on special order.

The following two issues are crucial for the people with disabilities to take full advantage of social media [10]:

- A device or tool used by them should incorporate the potential of certain assistive technology;

- A social media platform or service should be designed to be accessible to those individuals.

\section{Opportunities to use social media on existing devices}

One of the factors influencing the effective use of people with disabilities is that the provision of their access to these technologies and resources.

There are a number of technological tools that support the access of persons with disabilities to social media [16]:

1. Mobile devices. The role of such devices in society is increasing day by day. Particularly, in recent years, everyone has already started using smartphones. The number of people using mobile devices in 2015 is estimated at 4 billion. This indicator is predicted to reach 5 billion in 2019 [17]. Mobile devices play a crucial role in supporting people with limited health capabilities. This is due to the development of certain assistive functions on those devices for the disabled.

A large number of applications on iPhone, Samsung, Nexus and other technology have been introduced. These apps help people with disabilities access the device. They include:

VoiceOver. This application enables the blind people to use iPhone. The name of the program automatically sounds whenever the user touches anywhere on the phone. Moreover, if 
the user receives a message, the device converts it to audio-information. Thus, the user is able to use the phone even if he/she does not see it [18].

Zoom. This application zooms in any object on the screen. Hence, people with a weak vision can use the phone capabilities [19].

Siri. It can be controlled by the voice of the user [20].

Voice Access. It also enables to control the device by voice on Android platform [21].

Large Text. Makes it easier to see the texts enhancing all written information on the screen [22].

Apparently, the use of these applications can expand the access to social media.

2. Internet and modern web technologies. Internet and web technologies play an important role in meeting the health needs of people with disabilities. This technology is the basis for social networks and provides the socialization of the individuals with disabilities and their access to diversity of services (distance learning, online education, e-health, etc.).

Modern approaches in this field aim at recovering the social status of the persons with disabilities, achieving their financial independence and social adaptation. The use of social services (market, restaurant, cinema, post office, school etc.) by the physically disabled people is often very difficult compared to healthy people. The use of transport, rent, property, and banking and other services and infrastructures, leisure and social activities are also challenging for persons with disabilities. The barriers facing these people can be grouped as follows: physical isolation; labor restrictions; disadvantaged due to the social and labor restrictions; environmental barrier; information barrier; emotional barrier, and communication barrier.

The Internet and modern web technologies are helping the disabled people to overcome these obstacles. Purchase and delivery of the goods from the Internet store, payment of utility services through Internet-banking, and purchase of newspaper and magazines through the Internet-library enables the socialization of these people. Being aware of the events happening around the world via the Internet, taking virtual tours to different cities of the planet or virtual excursions to the museums are also possible [23].

Most of the current events taking place around the world are reported through social networks. It helps the users to access information more easily. In this regard, an active participation of the people with certain restrictions in social networks is directly related to their socialization in the society.

3. Artificial intelligence technologies. One of the most evolving spheres of recent times is related to artificial intelligence. Of course, the problems the people with physical limitations encounter when using social media may not stay out of the scope of this field.

One of the applications used to help the disabled people is Mind Machine Interface (MMI) or Brain-Computer Interface (BCI). This app supports the people to control the robots with the thoughts. People who have physical restrictions can use social media more conveniently through these devices.

The studies conducted by the Massachusetts Institute of Technology in 2016 have led to the development of a new technology to help the people with hearing impairments reach out to other people. Hence, the person with hearing problems is wearing the gloves that can transmit information to the computer via Bluetooth and conveys this thoughts expressed by the gestures into the computer. The computer helps to understand that person better by converting this information into a voice. Apparently, in the future, this invention can play a very important role in the process of integrating people with hearing impairments [24]. This technology can also be used to integrate people with disabilities into social networks. Thus, large companies such as Facebook enable their software to be operated with human voice, and people can benefit from this network by using this voice converter device.

Facebook, one of the world's most powerful social networks, has made enough innovations in this area. The company has made use of artificial intelligence technologies to ensure its users to make better and more efficient use of Facebook. Thus, the company has provided a voice 
explanation of the images uploaded into the system through artificial intelligence components to provide the users with vision problems to better understand the images shared by some friends [25]. Through this change, the user with visual problems will be able to see his/her friend relaxing on the shore, playing the musical instrument, or eating with family. It should be noted that Facebook supports this app in 20 languages and on Android, iOS and web environment.

It should be noted that certain work is also carried out in this area in Azerbaijan. For example, the Azerbaijani NeyroTex Company has developed the first pilot mini-computer controlled by the voice for blind and visually impaired people with the support of the Ministry of Transport, Communication and High Technologies and the Heydar Aliyev Foundation. The goal is to provide equal access to ICT for blind and visually impaired people.

The new device differs from the others by the absence of a monitor and keyboard, and all commands are controlled by a microphone. The mini-computer is equipped with the capabilities to get acquainted with the latest developments online through the voice commands, to use e-mail, to sound electronic texts, to accept and respond to phone calls. Computer software and all commands are in Azerbaijani language. The speech translation into Russian and English is also scheduled in the future [26].

Today, people with physical disabilities can read, write, visit, or even get acquainted with surroundings through ICT. Therefore, the catalysts role of ICT in this assistance process will always be important. All these technologies, of course, create favorable conditions for persons with disabilities to use social media.

\section{Opportunities of software applications supporting social media}

Today, social networking provides a variety of opportunities for physically restricted people to use social media. One of the best providers of these opportunities is Facebook. It should be noted that people with limited health capabilities may encounter certain questions when using these networks:

- What are the benefits of this software?

- How to install them?

- Where and how to apply if a problem arises?

For a complete clarification of these questions, each network should provide specific guidelines for its physically disabled users and ensure that their use of the system.

There are social media applications that are currently actively used in Azerbaijan. Here are some examples:

Facebook - according to statistics, currently 1.79 billion people worldwide are actively using this social network [27]. The corresponding indicator in Azerbaijan is 1 million 846 thousand people [28]. This network is designed to communicate with more friends, to create a group, to be informed about the opportunities provided by the companies. Obviously, this company, which has the largest market share in the world, is a social network that provides the most accessible opportunities for people with disabilities. Its page titled Facebook Accessibility publishes the updates related to the people with disabilities and offers new job opportunities for them [25]. The company has also developed guidelines for them. Additionally, the Facebook Add Captions project also offers new opportunities for the people with disabilities. This project provides the users with hearing problems to add subtitles to the videos shared on Facebook expanding their opportunities to understand videos [25].

LinkedIn - one of the most important software applications, though it does not have a large share in the social networking market. This network offers its users the opportunity to expand their careers and find new job opportunities. 


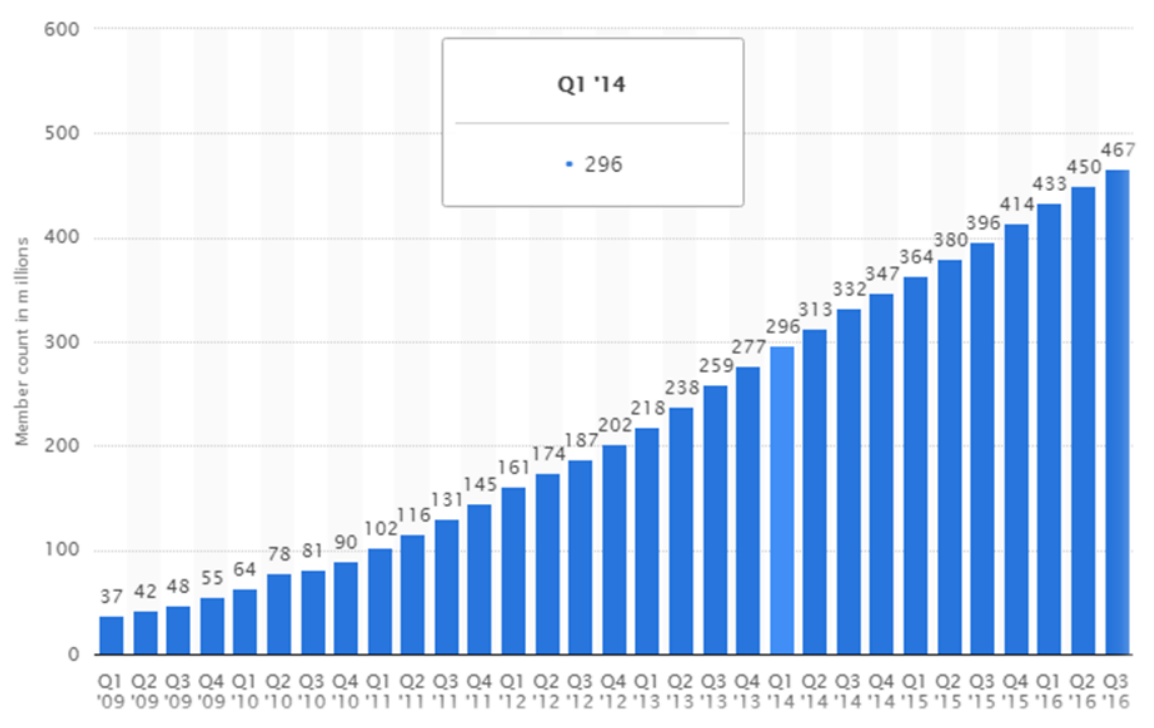

Figure 1. The growth dynamics of the users of LinkedIn for years 2009-2016

LinkedIn is of great importance for the people with health disabilities. Using this network they can find new jobs and even develop their careers. The network has 450 million users worldwide [29]. 143,000 of them are the users from Azerbaijan [30]. Figure 1 shows the growth dynamics of LinkedIn users for years 2009-2016.

Instagram is providing to share the images of the network users. Designed rather for entertainment, this software can be used to help people with disabilities to benefit from more enjoyable and exciting moments. 500 million people worldwide are actively using Instagram [31]. In Azerbaijan, this number is about a million [32]. Although Instagram is very actively used in the world, it has made few innovations in this area. It just created the disability hashtag. The users share their information gathering under this tag. Undoubtedly, ignorance of Instagram toward such a large user market can lead to lose the competition with other major social networking companies.

Figure 2 presents statistical data on the number of active users (million) in various social networks in 2017.

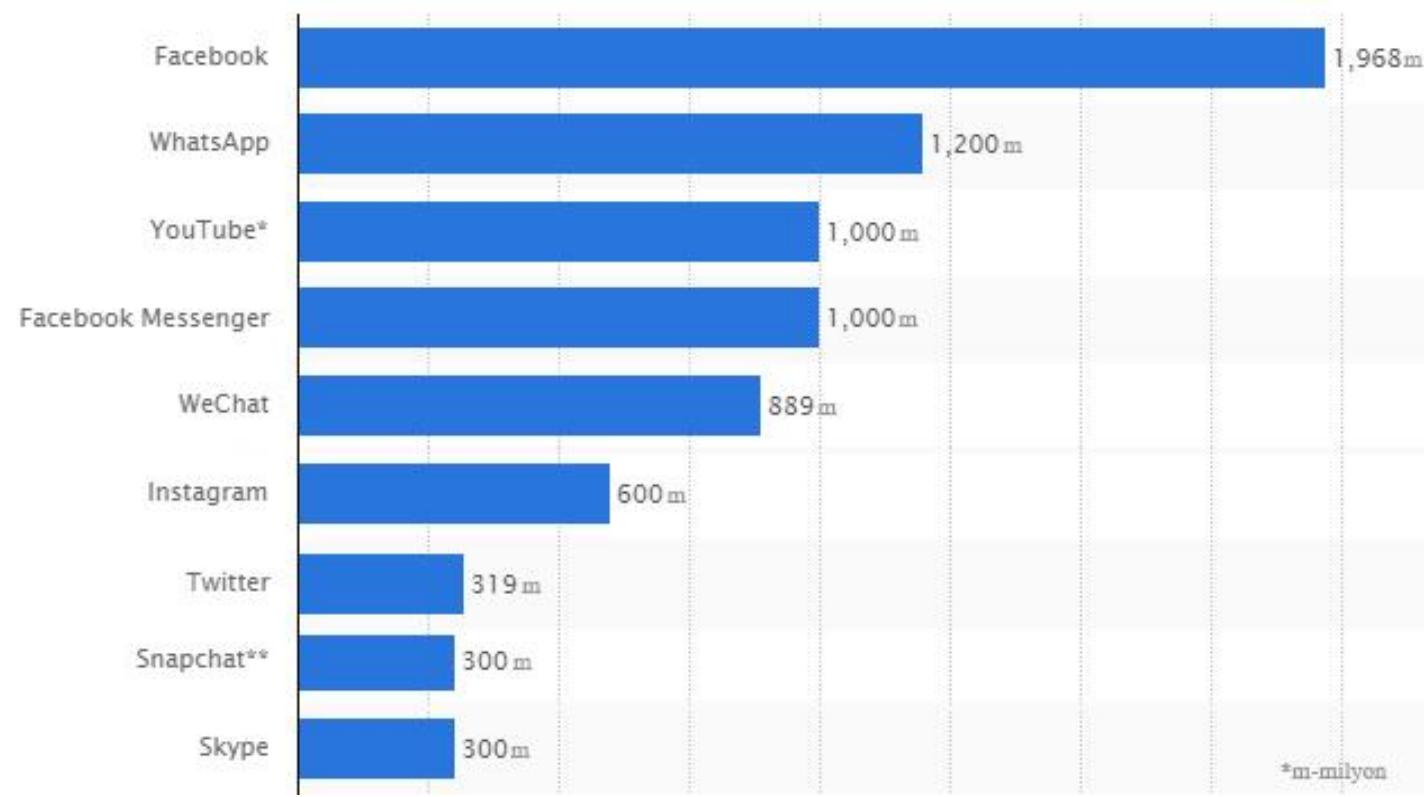

Figure 2. Number of active users in different social networks in 2017 ( $\mathrm{mln}$.) 
Skype - since it is used by both individual users and companies, it is crucial to increase the capabilities of disabled people to use this network. Being used by around 300 million people in the world, this software is also very popular in Azerbaijan [33]. Skype has also made a number of changes in this area and has increased the level of accessibility for the people with disabilities. For example, Skype screen readers, designed for Windows 8 , have made it easier for people with visual impairments to use the system [34].

Despite the fact that these social networks have a very important position in the world, their wide and comprehensive use by the disabled people has not yet been fully met. From this point of view, these companies have a great responsibility. With their help, the social media barrier to the disabled can be easily overcome.

\section{Problems faced by physically restricted people when using social media}

The above social networks can meet a number of needs of the people with limited health capabilities. However, not all disabled people can benefit from these resources. Thus, some of them do not have access to social networks, others do not use them for a variety of reasons, while some are even unaware of the existence of these resources.

Obviously, anyone who uses social media must first have access to the Internet. In order to ensure the use of social media by disabled people, first of all, this area should be thoroughly studied. The report of the Pew Research Center for 2015 revealed that only 54\% of people with disabilities had access to the Internet [35]. This, in turn, proves that there are still many problems in this direction.

Another problem facing people with disabilities is that both existing devices and social media platforms can not be used by those individuals. This problem has been still remained unsolved, though many companies offer some solutions in this regard. One of the main reasons preventing the use of social media by people with disabilities is the high cost of the technologies providing the access to these resources. The majority of the people with disabilities are unaware of the opportunities created by the government and companies for them. Thus, the problem of educating the people with limited health capabilities and organizing certain training courses for them arises.

The following suggestions are made to address the above-mentioned problems:

1. Provision of the use of ICT of the people with disabilities in each country shall be the basis for the social and economic integration of the citizens of this category.

2. Studies shall be conducted in order to determine the status of the Internet access and the use of social media by the people with disabilities.

3. ICT applications from existing technical tools for the people with limited health capabilities shall be developed and reasonable prices for them shall be offered to expand the access to these technologies.

4. Government shall play an important role in developing, stimulating and promoting ICT applications, and achieving affordability of these assistive technologies.

5. Individuals with limited physical capacities shall be regularly enlightened about the opportunities created by governments and companies being notified through media, social networking, online lectures, and presentations.

\section{Conclusion}

As a result of the widespread use of web technologies in recent years, social media has become a very important tool in the community. For the people without disabilities, this sector implies the opportunity to find new job opportunities, socialize, entertain, and learn about certain services, while for the people with disabilities it is a chance to integrate into society breaking down the barriers. From this point of view, the use of this system is of great importance for the people with disabilities. Facebook, Instagram, LinkedIn and Skype have a large share in the social media area. Though they have some integration efforts in this area, unfortunately they have not achieved 
the full resolution of the problem. In the modern era, when the social media becomes one of the key components of the society, the access to these resources is one of the most important steps towards integrating the people with disabilities into the society. Government, private companies and civil society should unite their efforts for improving the needs of these people with the needs of the disabled and developing new ICT applications. They should contribute to the realization of the mission of providing the equal ICT opportunities for each individual.

\section{References}

1. Kaplan A., Haenlein M. Users of the world unite!Retrieved 10 November 2011, http://www.openmediart.com/log/pics/sdarticle.pdf

2. World Health Organization, 2014,http://www.who.int/disabilities/en/

3. Khetarpall A. Information and Communication Technology (ICT) and Disability // Review of Market Integration, 2014, vol.6, no.1, pp.96-13.

4. The Union of Disabled People Organizations of the Republic of Azerbaijan http://www.udpo.az/qanunlar/index.html

5. Nabil E. Innovation and technology for persons with disabilities, 2013, http://www.un.org/esa/socdev/egms/2013/ict/innovation-technology-disaability

6. Gerasimenko A. IT and disabled people: rehabilitation and life in digits, https://www.3dnews.ru/560206/page-2.html

7. Mikheev A.M., "The Role of Social Networks in the Life of Minors with Disabilities," in The Scientific Journal "Service", 2014, vol. 8, No3, pp.16-21.

8. Using ICTs promote education and job training for persons with disabilities,http://www.connectaschool.org/sites/default/files/Mod4_executive

9. Empowerment of people with disabilities using ICT, 2010, http://www.makaia.org/english.shtml?apc=s1-1---\&x=2444.

10. Australian Communications Consumer Action Network (ACCAN) December 2012. SociAbility: social media for people with a disability, http://www.mediaaccess.org.au/web/social-media-for-people-with-a-disability

11. Kietzmann, J. Hermkens, K. McCarthy I. \& Silvestre, B. Social media? Get serious! Retrieved 12 November 2011, http://www.sciencedirect.com/ science/article/pii/S0007681311000061

12. Lysenko A.E. A look at the development of the information society based on equal opportunities, http://www.emag.iis.ru/arc/infosoc/emag.nsf/BPA/d4c5c4a219e12635c32576d70032

13. Computers and we, https://www.lifehacker.ru/2014/10/15/texnologii-dlya-slepyh

14. Assistive Technology Act of 1998. U.S. Government Printing Office, 1998, http://www.section 508.gov/assistive-technology-act-1998

15. Assistive Technology: Building Bridges, 2015, http://www.abilities.com/community /assistive_technology.html

16. Mammadova M., Guliyeva N., Ahmadov S. The role of ICT in the process of integration of people with disabilities into the society / Proceedings of the first republic scientific-practical conference on "Multidisciplinary problems of electronic medicine", Baku, 24 May 2016, pp.273-276.

17. Bellini J. The Statistics Portal, Avqust, 2015, http://www.statista.com/statistics/274774/forecast-of-mobile-phone-users-worldwide/

18. Apple, Accessibility IOS Voice Over, 2013, http://www.apple.com/accessibility/ios/voiceover

19. Apple, Accessibility IOS, 2011,http://www.apple.com/accessibility/ios

20. Apple Inc şirkəti, 2009, http://www.apple.com/ios/siri

21. Google, Voice Access, 2011, ttps://www.support.google.com/accessibility/android\#topic=6151842 
22. Google, Large Text, 2010,

https://www.support.google.com/accessibility/android/answer/6006972?hl=en

23. Empowerment of people with disabilities using ICT, https://www.makaia.org/english.shtml?apc=s1-1--- \&x=2444

24. Speech-Language and Hearing Associates of Greater Boston, PC, https://www.spedchildmass.com

25. Facebook aids Disability, https://www.facebook.com/accessibility

26. https://www.dilmanc.az

27. World Facebook users, November 2016, http://www.zephoria.com/top-15-valuable-facebookstatistics

28. Azerbaijan Facebook page statistics, June 2016, http://www.internetworldstats.com/asia.htm

29. Linkedİn users worldwide, October 2016, $\mathrm{http} / / / \mathrm{www}$.statista.com/statistics/274050/quarterly-numbers-of-linkedin-members

30. Azerbaijan LinkeIn page statistics, November 2016, http://www.linkedin.com/topic/azerbaijan

31. Instagram users worldwide, June 2016, http://www.statista.com/statistics/253577/number-ofmonthly-active-instagram-users

32. Instagram users in Azerbaijan, 28 October 2016, http://www.orkhanrza.com/en/tag/azerbaijan-instagram-users

33. Skype users worldwide, June 2016, http://www.statista.com/statistics/272014/global-socialnetworks-ranked-by-number-of-users

34. Skype help for disabled people. January 2017, http://www.support.skype.com/en/faq/FA12371/what-accessibility-features-are-availablefor-skype

35. How People with Disabilities Use Social Media, 512-356-1627, 2016 January,http://www.safeaustin.org/wp-content/uploads/2016/06/SafePlace-DRTx-Peoplewith-Disabilities-Social-Media-Report-Final.pdf 